\title{
Awareness of Kindergarten Parents About Developmental Learning Difficulties In of The Light Variables in Jubail Industrial City
}

Kowthar Ali ${ }^{1,}$ Huda Alshami ${ }^{2,}$ Noor Alotaibi ${ }^{3}$, Malak Alsiari ${ }^{4}$, Bushra Alabbasi ${ }^{5}$, Anwar Althaniyan $^{6}$

Department of Special Education, College of Science and Humanities, Imam Abdulrahman Bin Faisal University

\begin{abstract}
The aim of this study is to explore parents' awareness of developmental learning difficulties among kindergarten children in the light of the tow variables (sex and educational qualification). The study sample consisted of (20) Parent of children with developmental learning difficulties in Jubail city. The study follows a descriptive approach. To achieve the objectives of the study, a questionnaire developed by the researchers was used for measuring the awareness of parents. The study found that the awareness of kindergarten parents about developmental learning difficulties is higher than the average, and there are no statistically significant differences at the level of $(0.05)$ or less between the ample regarding the sex and educational qualification. The study recommended providing workshops to increase the parents' awareness about learning developmental.
\end{abstract}

Keywords: Awareness; Parents; Kindergarten children; Developmental learning Difficulties.

\section{Introduction}

In the past decades, interest in the field of special education has prevailed over certain forms of disabilities, such as mental, auditory, visual, and motor impairments. However, there is a group of children who have no apparent disability yet face some developmental and academic problems. This group of children does not reach enough attention leading to a significant deficit in one or more aspects of learning (Melhem, 2006). This deficit can be recognized through the academic achievements of children, which are often characterized by low levels (Mohammad, 2006). in Saudi Arabia, these children are referred to as having learning difficulties, which are divided into two types, academic and developmental. In this regard, learning difficulties in the 


\section{2nd World Conference on Teaching and Education}

19-21 February, 2021

Vienna, AUSTRIA

kindergarten stage appear in developmental learning skills, which are important and necessary for effective learning in the advanced grades.

Parents' awareness of the manifestations of learning difficulties plays an important role in the success of the school intervention (Alsemari, 2016). However, some parents do not notice the developmental difficulties that their child faces in the kindergarten stage, and this often leads to academic difficulties. Developmental learning difficulties can be defined as "The difficulties that deal with the pre-school processes that are represented in the cognitive processes related to attention, perception, memory, thinking, and oral language, and these processes form the most important foundations on which an individual's cognitive mental activity is based. Therefore, any disorder or defect that affects one or more of These processes necessarily leads to more difficulties later, and these difficulties may appear in a child of school-going age" (Abu Diyar, 2012, p. 123). Through the researchers practicing work in the kindergartens of the Royal Commission in Jubail, they noticed the unwillingness of parents to accept the development sessions for their children, or the lack of cooperation and participation, which may exacerbate the problems of later. Therefore, we seek through this study to identify the degree of parents' awareness about the developmental learning difficulties that appear on their child and the relationship of this awareness to the parent's gender and educational qualification. Specifically, the study attempted to answer the following research question:

RQ1: What is the degree of awareness of kindergarten parents about developmental learning difficulties?

This question can be broken into two sub-questions:

RQ2: Are there any differences between kindergarten parents' awareness according to the gender variable?

RQ3: Are there any differences between kindergarten parents' awareness according to the educational qualification variable?

\section{Methodology}

This study followed descriptive approach due to its relevance to the objectives of the research. descriptive approach aims to test hypotheses by collecting data (Al-Khalili, 2012).

\subsection{Participants}

Participants consisted of 20 parents of kindergarteners' children with developmental learning difficulties attending early intervention programs in Jubail Industrial City. The sample was diverse included 7 different kindergartens (see table 1)

Table 1 the number of participants from each kindergarten 


\section{2nd World Conference on Teaching and Education}

19-21 February, 2021

Vienna, AUSTRIA

\begin{tabular}{|l|c|c|c|}
\hline & Kindergarten & $\begin{array}{c}\text { Number of the } \\
\text { children }\end{array}$ & Percentage \\
\hline 1 & Darren Kindergarten & 3 & $15 \%$ \\
\hline 2 & Al Khozama Kindergarten & 3 & $15 \%$ \\
\hline 3 & Al Quds Kindergarten (1) & 3 & $15 \%$ \\
\hline 4 & Al Nakheel Kindergarten & 3 & $15 \%$ \\
\hline 5 & Al Hwailat Kindergarten (1) & 3 & $15 \%$ \\
\hline 6 & Rawdah Kindergarten & 3 & $15 \%$ \\
\hline 7 & Zarqa Kindergarten & 2 & $10 \%$ \\
\hline \multicolumn{2}{r|}{ Total } & 20 & $100 \%$ \\
\hline
\end{tabular}

\subsection{Characteristics of the participants}

A number of main variables have been identified to describe the participants of this study, including gender and educational qualification which have indicative indicators of the results of the study. In addition, these variables reflect the educational background of the participants and help to lay the foundations on which the various analyzes related to the study see table (2).

Table 2 Educational Qualification of Participants

\begin{tabular}{|c|c|c|c|c|c|c|}
\hline Gender & Number & Percentage & Percentage & $\begin{array}{c}\text { Educational } \\
\text { qualification }\end{array}$ & Number & Percentage \\
\hline Male & 4 & $\% 20.0$ & $\% 20.0$ & $\begin{array}{c}\text { Intermediate } \\
\text { degree }\end{array}$ & 1 & 5.0 \\
\hline Female & 16 & $\% 80.0$ & $\% 80.0$ & Bachelor's degree & 16 & 80.0 \\
\hline Total & 20 & $\% 100$ & $\% 100$ & $\begin{array}{c}\text { Master's degree } \\
\text { and higher } \\
\text { Total }\end{array}$ & 3 & 15.0 \\
\hline
\end{tabular}

\subsection{Instrument}

A questionnaire was developed following the Fathi Al-Zayat battery and the Michael Best scale. The questionnaire's main domains are attention, memory and perception. The questionnaire consisted of (35) items in its initial form. The five-point Likert scale 


\section{2nd World Conference on Teaching and Education}

19-21 February, 2021

Vienna, AUSTRIA

was used to obtain the responses of the study subjects, according to the following degrees of approval: (Strongly agree - agree - agree to some extent - disagree - strongly disagree). Each of the previous statements was giving a score, according to the following: Strongly agree (5) degrees, agree (4) degrees, agree to some extent (3) degrees, disagree (2) two degrees, strongly disagree (1) one score. In order to determine the length of the five Likert scale categories, the range was calculated by subtracting the upper bound from the lower bound $(5-1=4)$, and then dividing it by the largest value on the scale $(4 \div 5=0.80)$, and then was added This value is reduced to the lowest value on the scale (1); To determine the upper limit for this class. The length of the term was used to obtain an objective judgment on the averages of the responses of the study individuals, after treating them statistically. An electronic version of the questionnaire was developed using the Google Drive.

\subsection{Construct Validity}

Pearson's Correlation Coefficient was calculated; To identify the degree to which each of the questionnaire item is related to the total degree of the axis, as shown in Table (3):

3Table 3 Pearson correlation coefficients for axes phrases with overall score for each axis Table

It is clear from Table No. (3) that the values of the correlation coefficient of each of the items with its axis are positive, and statistically significant at the level of (0.01) or less. This indicates the validity of the internal consistency between the items of the three axis and their relevance to measuring what they were supposed to measure.

\subsection{Reliability}

Reliability of the tool was confirmed by the use of the Cronbach's Alpha ( $\alpha$ ). Table (4) shows the values of the constant coefficients for each axis of the questionnaire. 


\section{2nd World Conference on Teaching and Education}

\section{9-21 February, 2021}

Vienna, AUSTRIA

\begin{tabular}{|c|c|c|c|}
\hline The questionnaire & The Domains & $\begin{array}{c}\text { The Number of } \\
\text { Items }\end{array}$ & $\begin{array}{c}\text { The Reliability } \\
\text { Of the axis }\end{array}$ \\
\hline $\begin{array}{c}\text { Awareness of } \\
\text { kindergarten parents } \\
\text { about developmental } \\
\text { learning Disabilities in } \\
\text { light of some variables } \\
\text { in Jubail Industrial } \\
\text { City }\end{array}$ & Attention & 4 & 0.788 \\
\cline { 2 - 4 } & perception & 6 & 0.707 \\
\cline { 2 - 4 } & memory & 6 & 0.806 \\
\hline \multicolumn{2}{|r|}{ Reliability in general } & 16 & 0.895 \\
\hline
\end{tabular}

4 Table the Cronbach's Alpha tool

\begin{tabular}{|c|c|c|c|c|}
\hline \multirow{4}{*}{ The Domains } & The Items & $\begin{array}{c}\text { Dimension Correlation } \\
\text { Coefficient }\end{array}$ & $\begin{array}{c}\text { The } \\
\text { Items }\end{array}$ & $\begin{array}{c}\text { Dimension } \\
\text { Correlation } \\
\text { Coefficient }\end{array}$ \\
\hline \multirow{3}{*}{ Attention } & 1 & $0.779 * *$ & 4 & $0.685^{* *}$ \\
\cline { 2 - 5 } & 2 & ${ }^{* *} 0.802$ & 5 & ${ }^{* *} 0.783$ \\
\cline { 2 - 6 } & 3 & ${ }^{* *} 0.816$ & 6 & ${ }^{* *} 0.651$ \\
\hline \multirow{3}{*}{ perception } & 7 & ${ }^{* *} 0.665$ & 10 & ${ }^{* *} 0.762$ \\
\cline { 2 - 6 } & 9 & ${ }^{* *} 0.744$ & 11 & ${ }^{* *} 0.767$ \\
\hline \multirow{3}{*}{ memory } & 13 & ${ }^{* *} 0.794$ & 12 & ${ }^{* *} 0.645$ \\
\cline { 2 - 6 } & 14 & ${ }^{* *} 0.741$ & 16 & ${ }^{* *} 0.620$ \\
\cline { 2 - 6 } & 15 & ${ }^{* *} 0.611$ & - & - \\
\hline \multirow{2}{*}{} & & ${ }^{* *} 0.769$ & - & - \\
\hline
\end{tabular}

Table (4) shows a high general constant coefficient, reaching (0.895), and this indicates that the questionnaire reliable and can be relied upon in the field work of the study.

\subsection{Procedures}

The researchers contacted the teachers of developmental learning difficulties in the Royal Commission Kindergarten in Jubail, in order to send the questionnaire 


\section{2nd World Conference on Teaching and Education}

19-21 February, 2021

Vienna, AUSTRIA

electronically to the parents of children with developmental learning difficulties, and they followed up on the parents 'responses to the questionnaire, then collected the data and analyzed it statistically.

\subsection{Data analysis}

Data were analyzed statically using SPSS, and the following statistical measures were calculated:

1- Frequencies and percentages; to identify the characteristics of the study sample and determine their responses to the items of the main axes of the study tool.

2- Weighted Mean; this is to identify the average responses of the study sample to each of the items of the axes, and it was also useful for arranging the items according to the highest weighted mean.

3- Mean; This was to find out how high or low the responses of the study sample were from the main axes, and it helped arranging the axes according to the highest average

4- Standard Deviation; to identify the extent of the responses' deviation of the study sample to each of the items of the study variables, and for each of the main axes, from their mean. It is noticed that the standard deviation shows the dispersion in the responses of the study sample for each of the items. The more its value approaches zero, the responses are concentrated, and their dispersion decreases.

5- Mann-Whitney test to investigate the differences between the trends of the study sample according to their variables, which are divided into two categories.

\section{Results and discussions}

in this part, the researchers review the results of the statistical analysis of the research questions, their interpretation and discussion in light of the literature and previous studies.

The main question of this study is: What is the degree of awareness of kindergarten parents about developmental learning difficulties?

To answer this question, the mean of the tool's dimensions was calculated to determine the degree of awareness of kindergarten parents of developmental learning difficulties in Jubail, as shown in Table (5): 


\section{2nd World Conference on Teaching and Education}

19-21 February, 2021

Vienna, AUSTRIA

Table 5 the mean of the domains

\begin{tabular}{|c|c|c|c|c|}
\hline $\mathbf{N}$ & The Domains & Mean & $\begin{array}{c}\text { standard } \\
\text { deviation }\end{array}$ & $\begin{array}{c}\text { The } \\
\text { ranked }\end{array}$ \\
\hline 1 & Attention & 3.73 & 0.586 & 1 \\
\hline 2 & perception & 3.50 & 0.554 & 2 \\
\hline 3 & memory & 3.29 & 0.595 & 3 \\
\hline $\begin{array}{c}\text { Awareness of kindergarten parents } \\
\text { about developmental learning } \\
\text { Disabilities in light of some variables } \\
\text { in Jubail Industrial City }\end{array}$ & 3.51 & 0.508 & - \\
\hline
\end{tabular}

It is clear from Table No. (5) that the degree of awareness of kindergarten parents about developmental learning difficulties in Jubail city is tending to rise, as the total of the dimensions (attention, perception, memory) came with a mean of (3.51) and a standard deviation (0.508), and the first dimension (attention) came with a mean of (3.73) and a standard deviation (0.586), followed by the second dimension (perception) with a mean of (3.50) and a standard deviation (0.554). Finally, the third dimension (memory) came with a mean of (3.29) and a standard deviation (0.595).

This result is based on the developmental theory, which explains the developmental learning difficulties, that human growth in general and the growth of the cognitive aspect in it, are subject to a sequential pattern of stages, in which the previous stage is paved for the next stage, and that each stage has its own characteristics in terms of function and structure, and there is an interactive relationship between the level of maturity and learning tasks for the individual (Suhail, 2012). The result of this study is in the line with the study of Al-Samari (2016) as the researcher found positive views in the learning difficulties programs represented in the effectiveness of the program, communication with parents and their participation in their child intervention program. The researchers explain this result from perceptual theory as Nasrallah and Mazal (2011) stated that students with learning difficulties face obstacles in perception, such as visual perception, auditory perception and haptic perception. The researchers believe that as parents can clearly notice the perception problems that their child faces through some behaviors such as failure to recognize and distinguish between images, or the inability to hold the pen, they search for the causes of the problem and thus raise their level of awareness. The researchers also attribute this result to the prevalence rate of attention deficit in children compared to other developmental difficulties. For example, Samara (2015) indicated that attention deficit is the most common among children, as 


\section{2nd World Conference on Teaching and Education}

19-21 February, 2021

Vienna, AUSTRIA

the number of people affected by it is about $5 \%$ of the total world population, so education authorities payed attention to this problem and provided parents with free workshops to raise their awareness toward attention deficit.

The second question of this study is: Are there any differences between kindergarten parents' awareness according to the gender variable?

To answer this question Mann-Whitney Test was used to clarify the significance of the differences between the participant's responses according to the sex variable and the results came as shown in Table (6):

Table 6 participant's awareness according to the sex

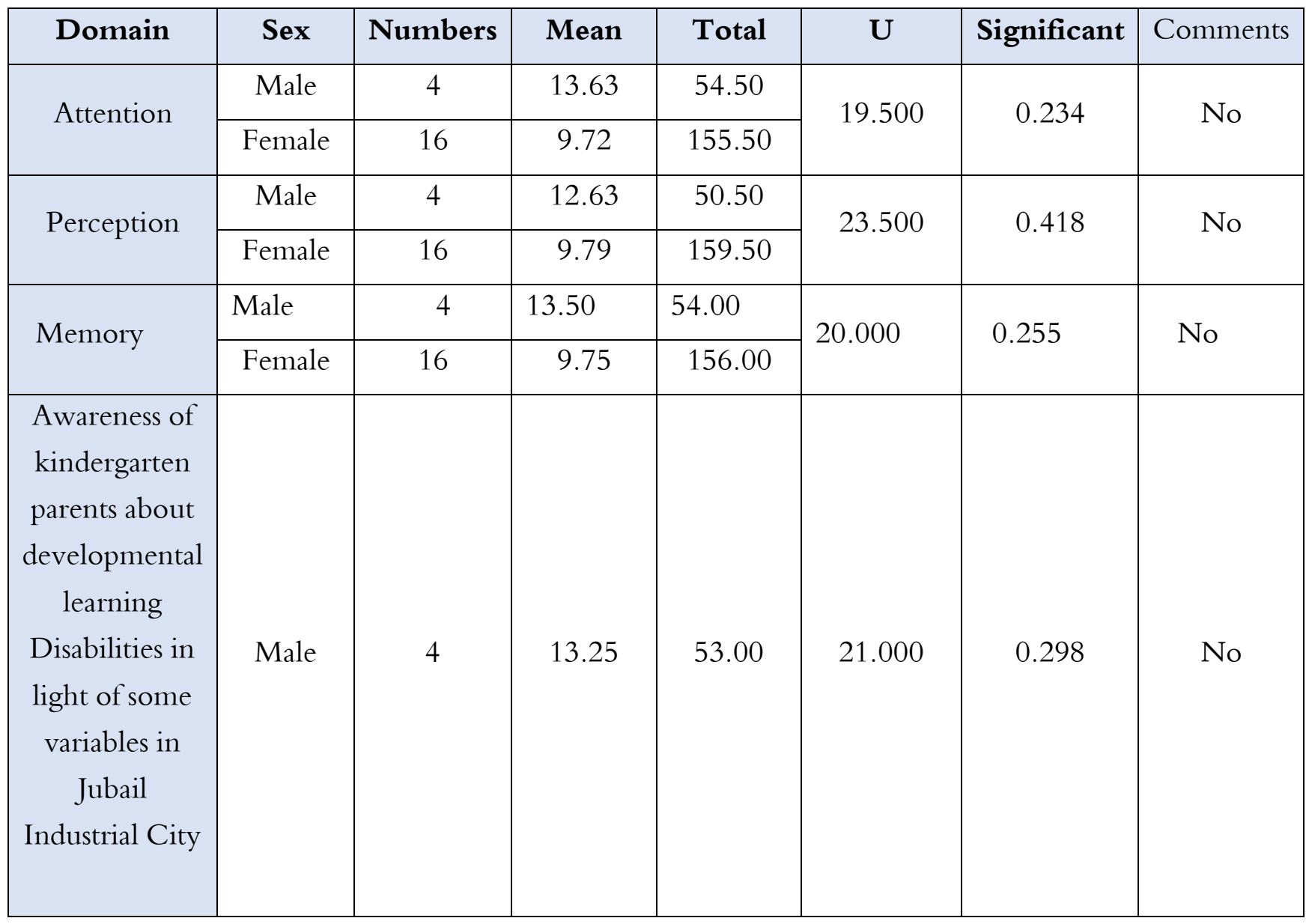




\section{2nd World Conference on Teaching and Education}

19-21 February, 2021

Vienna, AUSTRIA

\begin{tabular}{|c|c|c|c|c|c|c|c|}
\hline Domain & $\begin{array}{l}\text { educational } \\
\text { qualification }\end{array}$ & $\mathbf{N}$ & Mean & Total & $\mathbf{U}$ & Significant & comments \\
\hline \multirow{2}{*}{ Attention } & Undergraduate & 17 & 10.03 & 170.50 & \multirow{2}{*}{17.500} & \multirow{2}{*}{0.394} & \multirow{2}{*}{ No } \\
\hline & Postgraduate & 3 & 13.17 & 39.50 & & & \\
\hline \multirow{2}{*}{ Perception } & Undergraduate & 17 & 9.74 & 165.50 & \multirow{2}{*}{12.500} & \multirow{2}{*}{0.165} & \multirow{2}{*}{ No } \\
\hline & Postgraduate & 3 & 14.83 & 44.50 & & & \\
\hline \multirow{2}{*}{ Memory } & Undergraduate & 17 & 10.74 & 182.50 & \multirow{2}{*}{21.500} & \multirow{2}{*}{0.671} & \multirow{2}{*}{ No } \\
\hline & Postgraduate & 3 & 9.17 & 27.50 & & & \\
\hline \multirow{2}{*}{ Total } & Undergraduate & 17 & 10.09 & 171.50 & \multirow{2}{*}{18.500} & \multirow{2}{*}{0.458} & \multirow{2}{*}{ No } \\
\hline & Postgraduate & 3 & 12.83 & 38.50 & & & \\
\hline
\end{tabular}

It is clear from Table No. (6) that there are no statistically significant differences at the level of (0.05) or less in the average degrees of awareness of kindergarten parents about developmental learning difficulties in Jubail Industrial City, according to the difference in the gender variable. this result is partly consistent with the study of Al-Nusayri (2019), which showed that there were no statistically significant differences at the level of $(\alpha \leq 0.05)$ on learning difficulties teachers about the elements of the classroom environment according to the gender variable. The researchers attribute this result to the fact that the parent variable, whether male or female receives adequate care by Saudi Arabia through providing all support for the family and the child, and educational institutions are requested to improve their communication with the parents and enhance their role in the child learning process.

The third question of the study is: Are there any differences between kindergarten parents' awareness according to the educational qualification variable?

To answer this question Mann-Whitney Test was used again to clarify the significance of the differences between the participant's responses according to the educational qualification variable and the results came as shown in Table (7):

Table 7 Man-Whitney test

It is clear through the results shown in Table No. (7) that there are no statistically significant differences at the level of (0.05) or less in the attitudes of the study individuals regarding the difference in the educational qualification variable. This 


\section{2nd World Conference on Teaching and Education}

19-21 February, 2021

Vienna, AUSTRIA

question was based on the statement of Rafiqah (2014) as he referred to the role that the educational level of parents plays in developing their children's tendencies in a conscious and deliberate way, and its role on the child's academic achievement as they work in early age to provide rich learning environment that help their child acquire various learning skills. This result is in agreement with of Al-Baz and Petal (2016), where their study results showed that there were no statistically significant differences in the level of awareness of learning difficulties among kindergarten teachers according to the qualification variable. The researchers attribute this result to educational degree of most parents (Bachelor). This is maybe due to the support provide to all citizens through equality in learning opportunities as Saudi Arabia one of the countries that offers free education until university stage.

\section{Conclusion}

1- The awareness level of parents of kindergarten children regarding developmental learning difficulties is higher than the average with a statistically significant degree.

2- There are no statistically significant differences at the level of (0.05) or less in the attitudes of parents about (attention, perception, memory, awareness of parents of children with developmental learning difficulties among kindergarten children in Jubail Industrial City) according to the sex variable.

3- There are no statistically significant differences at the level of (0.05) or less in the attitudes of parents about (attention, perception, memory, and awareness of parents of children with developmental learning difficulties among kindergarten children in Jubail Industrial City) according to the educational qualification variable.

\section{Research recommendations:}

In light of the results obtained, the researchers recommended the following:

1- Providing awareness programs and workshops on developmental learning difficulties in Jubail, Kingdom of Saudi Arabia.

2- Working on removing the obstacles that limit the early detection of developmental learning difficulties in Jubail Governorate, Kingdom of Saudi Arabia.

3- Focusing on improving the knowledge and skills of mothers with developmental learning difficulties in Jubail Governorate, Saudi Arabia as mother's role is significant in early childhood.

4- Including parents with higher education degree in the process of community awareness in developmental learning difficulties. 


\section{2nd World Conference on Teaching and Education}

19-21 February, 2021

Vienna, AUSTRIA

\subsection{Future studies:}

1- Conducting future studies on the effectiveness of awareness programs on developmental learning difficulties in kindergarten.

2- Conducting future studies on the role of educational institutions in raising awareness of developmental learning difficulties in the kindergarten stage

3- Conducting future studies on family needs regarding knowledge and skills to identify developmental learning difficulties in the early stage.

4- Conducting future studies on the effectiveness of training programs based on methods of teaching children with developmental learning difficulties

\section{Arabic references:}

Abdul-Salamah, Areej and Sheikha, Maha. (2010). Early intervention in children with learning difficulties. King Saud University, Riyadh, Kingdom of Saudi Arabia.

Abu Al-Diyar, Massad. (2012). Dictionary of Learning Disabilities Terms and Vocabulary (2nd ed.). Kuwait: Child Education and Assessment Center. Retrieved from https://cutt.us/EnaU0.

Al-Baz, Noura, and Al-Batal, Zaid. (2016). The level of awareness of indicators of learning difficulties among kindergarten teachers in Riyadh. Journal of Special Education and Rehabilitation: The Institution for Special Education and Rehabilitation, 4 (15), 38-75. Retrieved from http://search.mandumah.com/Record/803534.

Al-Farra, Ismail. (April 2005). Early diagnosis of learning difficulties in kindergarten children from the point of view of special education. A study presented at the Special Education Conference, Reality and Hope, University of Jordan, College of Education, Jordan.

Al-Hantushi, Abbas. (2017). The role of the family in enhancing the educational role to build future generations. The Specialized Educational International Journal, 6 (6), 185-197.

Retrieved from http://search.mandumah.com/Record/845753.

Al-Khalili, Khalili. (2012). Fundamentals of educational scientific research. Dubai, United Arab Emirates: Dar Al-Qalam Publishing. And distribution.

Al-Samari, Abdullah. (2016). The effectiveness of learning difficulties 


\section{2nd World Conference on Teaching and Education}

19-21 February, 2021

Vienna, AUSTRIA

programs from the point of view of parents of pupils who have learning difficulties at the primary level. Journal of Special Education and Rehabilitation: The Institution for Special Education and Rehabilitation, 4 (13), 294-325.

Kenawy, Hoda. (2005). Entrance to kindergarten. Riyadh: Al-Rashed Library.

Melhem, Sami. (2006). learning difficulties. March House for Publishing and Distribution, Amman.

Muhammad, Adel. (2006). Batteries for tests of some pre-academic skills for kindergarten children as indicators of learning

Muhammad, Adel. (2009). Some cognitive variables for kindergarten children with lack of academic skills as an indicator of learning difficulties. College of Education, Al-Zaqiq University.

Nasrallah, Omar and Mazal, Omar. (2011). Learning difficulties and language problems (their nature - diagnosis - treatment). Wael Publishing House: Amman.

Refkh, yakhlf. (2104). The cultural level of the family has an impact on the academic achievement of children. The Wisdom Journal for Educational and Psychological Studies, 2 (4).

Saber, Mervat, and Ahmed, Mona. (2017). The effectiveness of the Portage (early intervention) to develop the awareness of mothers of children with learning difficulties and the development of some sensory and cognitive skills of their children in early childhood. Journal of Childhood Studies: Ain Shams University - Graduate School of Childhood, 20 (76), 179-193. Retrieved from http://search.mandumah.com/Record/862473

Samara, Aziz. (2015). Child Psychology (3th ed). Amman, Jordan: House of Thought Publishing.

Sawalha, Aounia. (2019). The effectiveness of a proposed training program to improve the level of knowledge of mothers of students with learning difficulties in the city of Amman about learning difficulties. Journal of the Islamic University for Educational and Psychological Studies: The Islamic University of Gaza - Scientific Research Affairs and Graduate Studies, 27 (6), 642-662. Retrieved from http://search.mandumah.com/Record/997277

Suhail, Tamer. (2012). Learning difficulties between theory and practice. Deanship of Scientific Research and Postgraduate Studies, AlQuds Open University, Ramallah, Palestine.

\section{Foreign references:}




\section{2nd World Conference on Teaching and Education}

19-21 February, 2021

Vienna, AUSTRIA

Sahu, A., Bhargava, R., Sagar, R., \& Mehta, M. (2018). Perception of Families of Children with Specific Learning Disorder: An Exploratory Study. Indian journal of psychological medicine, 40(5), 406-413.

https://doi.org/10.4103/IJPSYM.IJPSYM_148_18.

Chen, Ying-Shu. (2008). The Nature of Teacher-Student

Interactions during Communication Intervention for Young Children with Developmental Disabilities Including Severe/Multiple Developmental Disabilities. Doctor of Philosophy. The University of Texas atAustin, TE. Journal of Education and Health Promotion, 2, 30-46. Retrieved from https://search-proquest-

com.library.iau.edu.sa/docview/304473207?accountid=136546\&pq-origsite=summon 